\title{
PROPOSTA PARA O ENSINO DA CONTROLADORIA AMBIENTAL NOS CURSOS DE GRADUAÇÃO DE CIÊNCIAS CONTÁBEIS NAS IESs BRASILEIRAS
}

\author{
Sonia Maria da Silva Gomes \\ Doutora em Engenharia de Produção pela Universidade Federal de Santa Catarina - UFSC \\ Professora da Universidade Federal da Bahia - UFBA \\ soniagomes3@gmail.com \\ Márcio Santos Sampaio \\ Mestre em Contabilidade pela Universidade Federal da Bahia - UFBA \\ Professor da Universidade do Estado da Bahia - UNEB \\ marcio_sampaio1@ @otmail.com \\ Tânia Cristina Azevedo \\ Mestre em Contabilidade pela Fundação Visconde de Cairu - FVC \\ Professora da Universidade Federal da Bahia - UFBA \\ vilma.geni@fecap.br \\ Vilma Geni Slomski \\ Doutora em Educação pela Faculdade de Educação da Universidade de São Paulo - FEUSP \\ Professora do Centro Universitário Álvares Penteado - FECAP \\ vilma.geni@fecap.br
}

\section{RESUMO}

O objetivo deste trabalho é apresentar uma proposta de ensino da Controladoria Ambiental nos Cursos de Ciências Contábeis das Instituições de Ensino Superior (IES) brasileiras. As evidências empíricas têm indicado que a inserção dos conceitos de Contabilidade Ambiental nos cursos de graduação contribui para a formação do profissional de Contabilidade (Gray, Owen e Maunders (1987); Blundell e Booth (1988); Gray (1990); Gray, Bebbington e Walters (1993). Pelo fato de os estudantes serem os futuros tomadores de decisões corporativas, a inserção da variável ambiental na educação é um tema importante e as instituições de negócios deveriam encorajar esta prática. O modelo de ensino atual sobre as questões socioambientais é fragmentado e disciplinar (contabilidade financeira ambiental e contabilidade gerencial ambiental). Como contribuição, propõe-se um modelo de ensino interdisciplinar, alicerçado no paradigma da sustentabilidade. Assim, as disciplinas do curso devem focar temas transversais, tais como desenvolvimento sustentável; responsabilidade social corporativa e contabilização das ações de prevenção e recuperação ambiental.

Palavras-chave: Contabilidade ambiental; Curso de Ciências Contábeis; Ensino de Controladoria Ambiental; Sustentabilidade.

\section{PROPOSAL FOR ENVIRONMENTAL MANAGEMENT ACCOUNTING EDUCATION OF UNDERGRADUATE COURSES IN ACCOUNTING IN HIGHER EDUCATION INSTITUTIONS IN BRAZIL}

\begin{abstract}
The aim of this paper is to present a proposal for teaching courses in Controlling Environmental Accounting Sciences Education Institutions (HEIs) in Brazil. Empirical evidence has indicated that the insertion of the concepts of environmental accounting in undergraduate courses contributes to the formation of professional accounting (Gray, Owen and Maunders, 1987; Blundell and Booth, 1988; Gray, 1990; Gray, Bebbington, and Walters, 1993). Students are the future corporate decision makers and the insertion of variable environmental education is an important issue and business institutions should encourage this practice. The current model of education on social and environmental issues (financial accounting and Environmental Management Accounting Environmental) is a fragmented discipline. Insufficient training of accounting professionals contributes to social and environmental issues. We propose a model for interdisciplinary teaching / holistic, based on the paradigm of sustainability, which represents a continuous process able to prevent the ruin of a system for ensuring access and replacement of goods and services. All subjects in the course should focus on cross-cutting themes such as sustainable development, corporate social responsibility, and accounting of prevention and recovery environment.
\end{abstract}

Keywords: Sustainability; Environmental Accounting; Management Accounting; Accounting Course; Environmental Education. 


\section{INTRODUÇÃO}

A contabilidade ambiental tem emergido como uma linha de investigação importante para área contábil, todavia esse assunto continua como um assunto periférico na formação do profissional de contabilidade. Ainda que as pesquisas empíricas comprovem a importância da inserção dos conceitos de Contabilidade Ambiental nos cursos de graduação contribui para a formação do profissional de Contabilidade (Gray, Owen e Maunders (1987); Blundell e Booth (1988); Gray (1990); Gray, Bebbington e Walters (1993) e Gray, Bebbington e Mcphail (1994). Uma das dificuldades, apontadas pelos pesquisadores, para introdução da questão ambiental no currículo é que a prática de gestão ambiental é um assunto com enfoque multidisciplinar, faltam docentes qualificados e, esse assunto, na opinião de alguns coordenadores, não é imprescindível.

Todavia, pelo fato de os estudantes serem os futuros tomadores de decisões corporativas, a inserção da variável ambiental na educação é um tema importante e as instituições de negócios deveriam encorajar esta prática. O modelo de ensino atual sobre as questões socioambientais é fragmentado e disciplinar (contabilidade financeira ambiental e contabilidade gerencial ambiental). Além dos assuntos estarem desarticulados com outros componentes curriculares, o curso não prepara o profissional de contabilidade para atender a demanda do mercado por profissionais capazes de lidar com os problemas relacionados à sustentabilidade e suas possíveis soluções.

Como contribuição para que as questões socioambientais façam parte da formação dos profissionais de contabilidade, propõe-se um modelo de ensino interdisciplinar. Assim, propõe-se que as disciplinas do curso focam temas transversais, tais como desenvolvimento sustentável; responsabilidade social corporativa (triple bottom line) e contabilização das ações de prevenção e recuperação do meio ambiente.

Houve diversos estudos (Deegan e Gordon, 1996; Deegan e Rankin, 1996; Guthrie e Parker, 1990, Gray, 1996, Gibson, 1997, Ribeiro, 1992 e 2005; Ferreira, 1998 e 2003; Paiva, 2003; Tinoco e Kraemer, 2005, 2005) sobre questões ambientais. Apesar desta consciência, ainda é pequeno o número de empresas que divulgam informações socioambientais, de maneira voluntária e adequada. Isto pode ser devido à falta de conhecimento e conscientização dos atuais gestores e contadores sobre a compreensão da importância estratégica da contabilidade ambiental no processo de tomada de decisão, a fim de a empresa obter vantagem competitiva.

A contabilidade ambiental é um tema em discussão no Brasil desde o início da década de 1990. Assim, há necessidade de introduzir esse componente curricular na formação dos bacharéis em Ciências Contábeis para uma melhor compreensão das práticas de contabilidade e sua aplicação na tomada de decisão organizacional.

Neste contexto, uma tentativa foi feita para avaliar a compreensão dos estudantes de contabilidade sobre as questões ambientais. Diante deste contexto, este artigo objetiva apresentar uma proposta de ensino da Controladoria Ambiental nos Cursos de Ciências Contábeis das Instituições de Ensino Superior (IES) brasileiras.

\section{REFERENCIAL TEÓRICO}

$\mathrm{O}$ acelerado progresso proporcionado pela Revolução Industrial e as principais alterações nos modos de produção das empresas, impactou, de forma significativa, na captação de recursos naturais para o cumprimento dos objetivos organizacionais. Nas últimas décadas, a relação das entidades com esses recursos, além de tornar-se objeto de pesquisa de inúmeros estudos entre pesquisadores e ambientalistas, transformou-se em um desafio no que diz respeito ao desenvolvimento econômico sustentável, permeando as discussões entre empresas, governo e sociedade.

A importância que atualmente se atribui às questões ambientais é resultado do amadurecimento da sociedade nos últimos anos, quanto à capacidade de gerar riquezas com uso de recursos de ordem natural. Por muito tempo, a sociedade ficou alheia ao uso irracional de recursos e 
à degradação do ambiente, decorrente dos mecanismos de produção que vêm ao longo do tempo afetando a qualidade de vida e ao esgotamento dos recursos. Entretanto, as questões ligadas à proteção do ambiente, têm sido cada vez mais presentes, se refletindo na avaliação econômica das empresas e na escolha das ações por investidores, bem como na aquisição de produtos por parte dos consumidores.

Conforme evidenciado por Deegan (2002), o número de pesquisadores cresceu de forma significativa desde a década de 1990, sendo este crescimento amparado pelos periódicos que também publicaram um maior volume de trabalhos na área ambiental. Nascimento et al. (2009) verificaram o crescimento das pesquisas com esta temática socioambiental e evidenciaram que os autores que mais publicaram nos periódicos internacionais de língua inglesa no período de 1997 a 2007 foram Dennis Patten, Carol Adams, Nola Buhr e Rob Gray. Já os periódicos que mais publicaram artigos sob a temática socioambiental foram: Accounting, Auditing and Accountability Journal; Critical Perspective on Accounting; Accounting, Organizations and Society e The British Accounting Review.

Essa elevação nas pesquisas acadêmicas revela que a Contabilidade Ambiental possui uma grande parcela de responsabilidade na divulgação de informações que indiquem as ações empresariais no ambiente que elas estão desenvolvendo suas atividades para os seus stakeholders. Assim, os relatórios ambientais ganham destaque neste cenário e, nesse sentido, Epstein e Freedman (1994) verificaram que diversos grupos de usuários consideram os relatórios anuais como uma fonte importante de informações sobre o desempenho ambiental da organização.

Já as evidências empíricas, identificadas por Gray (1993), indicaram que a sociedade tem se conscientizado das consequências negativas do crescimento das empresas e, portanto, pressionam as empresas para a divulgação de relatórios ambientais. Todavia, na opinião de Nossa (2002), o que pode ser identificado é uma ausência de padronização em tais relatórios, o que dificulta a análise comparativa das empresas que desenvolvem ações adequadas para com o meio ambiente, tornando mais complexo à identificação das organizações com bom desempenho ambiental.

Essa crescente conscientização da sociedade acerca da responsabilidade empresarial com relação ao meio ambiente tem provocado um aumento da pressão sobre as organizações pela prestação de contas e divulgação de informações sobre as intervenções destas no ambiente, nas quais onde estão inseridas. Todavia, de acordo com Das, Sen e Pattanayak (2008), apesar do aumento no volume de evidenciação de informações ambientais, as empresas não divulgam adequadamente tais informações. Segundo esses autores isso se deve ao fato da ausência de preparação dos atuais gestores para a compreensão da inserção da contabilidade ambiental nas tomadas de decisões estratégicas.

Para otimizar essas decisões faz-se necessário incorporar na estratégia organizacional a discussão dos conceitos de sustentabilidade social, ambiental e econômica (triple bottom line). Assim, estes constructos estabelecem as diretrizes para a ação das empresas, desde a gestão dos recursos naturais, permeando todas as atividades e processos, até a divulgação das informações de natureza socioambiental para os diversos stakeholders da organização.

Embora as pesquisas empíricas apontem para necessidade de inserção das questões sociambientais na matriz curricular dos cursos de graduação, aqui no Brasil, segundo a pesquisa de Souza (2008) e Calixto (2006), esse assunto ainda é tratado de maneira superficial pelos coordenadores dos cursos.

De acordo com Clarkson, Richardson e Vasvari (2007), a contabilidade ambiental tem sido pesquisada sob três vertentes:

a) a primeira, avalia a relevância da informação para o desempenho organizacional. As pesquisas desenvolvidas sob esta vertente respondem a necessidade dos investidores em mensurar o passivo ambiental das organizações (Cornier, Magnan e Morard, 1993; Blacconiere e Patten, 1994;

Revista de Gestão Social e Ambiental - RGSA, São Paulo, v. 6, n. 1, p. 177-189, jan./abril 2012. 
Richardso e Welker, 2001).

b) a segunda vertente, ampara as pesquisas que investigam as variáveis que influenciam na decisão gerencial em evidenciar informações sobre o passivo ambiental. Desta forma, percebe-se que existem fatores estratégicos que condicionam a divulgação de informações acerca do passivo ambiental (Patten, 1992; Barth, Mcnichols e Wilson,1997: Cormier e Magnan, 2006).

c) já a terceira vertente suporta os estudos que buscam identificar a relação entre o disclosure socioambiental e o desempenho das empresas (Ingram e Frazier, 1980; Wiseman,1982; Freedman Wasley, 1990; Clarkson, Richardson e Vasvari, 2007).

No Brasil, há de se destacar que as informações de cunho ambiental são divulgadas de maneira segregada, de forma não consubstanciada, nos habituais relatórios do Balanço Patrimonial, Demonstração do Resultado do Exercício e com relativa superficialidade nas Notas Explicativas. Todavia, nos últimos anos, vários organismos têm estabelecido diretrizes, de caráter não obrigatório, entre essas destaca-se o Instituto Ethos cuja missão é “[...]mobilizar, sensibilizar e ajudar as empresas a gerir de forma socialmente responsável, tornando-as parceiras na construção de uma sociedade sustentável e justa".

Com atuação neste mesmo cenário, o Instituto Brasileiro de Análises Sociais e Econômicas - Ibase, criado em 1981, tem contribuído para o estabelecimento de diretrizes para publicação de informações sociais e ambientais relatados no Balanço Social. Segundo Paiva (2003), o Balanço Social é uma demonstração de gestão da informação que visa evidenciar, de forma plena, informações de natureza contábil, econômica, ambiental e social, sobre o desempenho das entidades, aos mais diferentes usuários. Também, no sentido de estabelecer procedimentos para a divulgação de informações sociais e ambientais, o Conselho Federal de Contabilidade (CFC) publicou a Norma Brasileira de Contabilidade (NBC) T-15 em 2004.

Com um alcance internacional, a Global Reporting Iniciative (GRI, 2010) tem contribuído para a elaboração de relatórios de sustentabilidade mais adequados, consistentes e padronizados, divulgando diretrizes sobre o conteúdo e forma de apresentação de tais relatórios. Segundo a GRI (2000, p.3), elaborar relatórios de sustentabilidade "[...]é a prática de medir, divulgar e prestar contas para stakeholders internos e externos do desempenho organizacional visando ao desenvolvimento sustentável". Esse relatório tem o objetivo de "[...]descrever os impactos econômicos, ambientais e sociais (tripple bottom line) de uma organização, como o relatório de responsabilidade social empresarial, o balanço social, entre outros".

Apesar do aumento da normatização sobre a evidenciação das informações de natureza ambiental, percebe-se que ainda não existe uma divulgação adequada de tais informações. Desta forma, a contabilidade, ao identificar, mensurar, registrar e interpretar os fatos internos e externos das ações empresariais colabora para o relato e a evidenciação das informações ambientais. $\mathrm{O}$ impacto das atividades empresariais no meio ambiente deve ser evidenciado pela Contabilidade, pois conforme Souza e Ribeiro (2004, p. 56) "[...]cabe a ela a elaboração e fornecimento de informações aos usuários internos e externos sobre eventos ambientais que causam modificações na situação patrimonial da entidade".

A divulgação de informações ambientais tem passado a formar o diferencial competitivo para algumas empresas e, tornado-se uma ferramenta estratégica para criação de valor e avaliação de risco. (Aerts, Cormier e Magnan, 2004 apud Farias, 2006). Nesse contexto, a contabilidade ambiental ganha relevância no processo de geração de informações e, principalmente, no apoio às decisões relacionadas à gestão estratégica da organização.

Nessa direção, faz-se necessário incorporar a tal discussão a opinião de Das, Sen e Pattanayak (2008) e Grinell e Hunt (2000), quando indicam que as informações ambientais ainda não atendem às necessidades do stakeholders, pois o processo de geração das informações ambientais reflete o processo de formação destes gestores, enquanto graduandos ou pósgraduandos. Esses autores indicam como solução para tal problema um curso que proporcione uma formação multi e interdisciplinar e com conteúdos capazes de potencializar o processo de tomada de 
decisão desses gestores.

Na opinião de Sefcik et al. (1997, apud Grinell e Hunt, 2000), a contabilidade ambiental pode ser incorporada aos cursos de contabilidade fornecendo um amplo conteúdo com o propósito de solidificar a educação contábil ambiental. De acordo com Grinell e Hunt (2000), a educação ambiental nos cursos de contabilidade deve proporcionar aos alunos a compreensão do papel da contabilidade como ferramenta de apoio à estratégia ambiental das organizações, bem como evidenciar como várias disciplinas do currículo contábil se inter relacionam com as questões ambientais. Assim, é de fundamental relevância discutir o processo de ensino da contabilidade e suas implicações na formação alunos/gestores, que serão disponibilizados para o mercado, quando serão desafiados a fornecerem informações ambientais, não só financeiras, mas também de caráter gerencial.

\subsection{O ensino da contabilidade ambiental}

O relatório da Association of Certified Accountants (Owen et al., 1994, p. i) não identificou "[...]qualquer resposta significativa dos profissionais de contabilidade para uma desenvolvimento social e ambiental " e afirmou que este desinteresse, possivelmente, decorre do ensino atual da contabilidade.

Bebbington et al (1994), afirmam que os contadores têm pouco envolvimento nas atividades ambientais de suas empresas. Isso é refletido pelo baixo grau de evidenciação de informações contábeis nos relatórios das empresas. Os autores argumentam que a principal razão para isso é a presente educação na área contábil, ela não prepara os contadores para os desafios do meio ambiente. Já Gibson (1997) realizou um estudo exploratório sobre o grau de aceitação/incorporação da variável ambiental na matriz curricular do curso de Ciências Contábeis de uma amostra de universidades dos seguintes países: Austrália, Nova Zelândia e Reino Unido. A análise permitiu identificar que os cursos combinam temas conceituais e teóricos na incorporação da contabilidade ambiental e o desenvolvimento de perspectivas alternativas, abordando temas como a mensuração, o gerenciamento de sistemas e o planejamento ambiental.

Além desta, há de se destacar a experiência de Grinell e Hunt (2000), com a formatação de curso de gestão de negócios com conteúdos de contabilidade ambiental. O curso foi dividido em três fases: a primeira, envolvendo uma revisão das dimensões globais acerca de degradação ambiental e do papel do governo na formação de políticas públicas; a segunda, referia-se a uma revisão do papel e da responsabilidade das empresas com relação às questões ambientais e, a terceira, discutia as dimensões contábeis relacionadas aos aspectos ambientais. Esta intervenção na formação dos futuros gestores proporcionou uma visão interdisciplinar, crítica e reflexiva a respeito das questões ambientais e, principalmente, sobre a responsabilidade das empresas com relação a tais questões.

Das et al. (2008) realizaram uma pesquisa para avaliar a percepção dos alunos do curso de graduação em Administração, na Índia, sobre a utilidade das informações contábeis ambientais no apoio das estratégias e da avaliação de desempenho ambientais corporativa. Para tanto, foi oferecido um curso de contabilidade ambiental, a uma amostra de 28 alunos. Aplicou-se um questionário a esses estudantes antes e depois da realização do curso, a fim de compreender a diferença do seu nível de percepção. Os resultados sugerem uma diferença significativa no nível de percepção dos alunos sobre a utilidade da incorporação de competente curricular contabilidade ambiental no curso de graduação de Administração, para apoiar o processo de tomada de decisão dos futuros gestores no contex to de desenvolvimento sustentável.

Outras pesquisas têm recomendado a introdução dos conteúdos de contabilidade ambiental nos curso de Contabilidade, como meio de ampliar a conscientização e os horizontes dos profissionais de contabilidade para compreender os problemas políticos, sociais e econômicos, tais

Revista de Gestão Social e Ambiental - RGSA, São Paulo, v. 6, n. 1, p. 177-189, jan./abril 2012. 
como Das, Sen e Pattanayak (2008), Blundell e Booth (1988), Gray (1990), Gray, Bebbington e Walters (1993), Gray, Bebbington e Mcphail (1994), Gray, Owen e Maunders (1987) e Sefcik et al (1997).

As pesquisas desenvolvidas por Lewis et al. (1992) e Mathews (1994) evidenciaram as barreiras relacionadas à inserção de temas atualizados no currículo contábil. Já Gray et al. (1994) e Puxty et al. (1994) realçaram a carência de programas adicionais para corrigir a ausência de percepção de problemas ambientais na educação contábil corrente. Por sua vez, Probert (2002) empreendeu um estudo acerca das principais dificuldades, bem como quais as principais lições que podem ser aprendidas sobre educação ambiental dos futuros gestores. Na opinião desse autor, uma das dificuldades na incorporação dos conteúdos ambientais no currículo dos cursos de Ciências Contábeis é que a prática da gestão ambiental exige um enfoque multidisciplinar. Assim, pelo fato dos estudantes estarem inseridos no processo decisório das organizações, a inclusão da variável ambiental na formação destes torna-se relevante.

No Brasil, Barbieri e Sousa (2005) desenvolveram um estudo sobre a inserção da componente curricular educação ambiental nos cursos de graduação em Administração e verificaram que a maioria dos cursos já realizou a implementação dessa disciplina. Calixto (2006) pesquisou o grau de inserção da componente curricular contabilidade ambiental na matriz curricular dos cursos de graduação em Ciências Contábeis oferecidos por universidades brasileiras, a importância desta componente curricular, na visão dos coordenadores, e as possíveis dificuldades para sua inclusão nos respectivos cursos. Os resultados obtidos indicaram que a componente curricular é oferecida por um número reduzido de universidades, porém, para a maioria dos coordenadores, o componente curricular é considerado importante na formação dos acadêmicos, sendo que a maior dificuldade para incluir a componente curricular nos cursos de Ciências Contábeis é a adaptação da matriz curricular no sentido de atender a uma série de temas emergentes relevantes para a formação do contador.

Estes resultados foram corroborados por Souza (2006), que pesquisou nas Instituições de Ensino Superior a componente curricular Contabilidade Ambiental na matriz curricular do curso de graduação em Ciências Contábeis, identificando apenas 26 cursos, das 916 IESs que o oferecem o curso. Adicionalmente, investigou a evolução das publicações em periódicos acadêmicos e livros relacionados ao tema publicados nos últimos quatro anos no Brasil, verificou que houve um aumento substancial das publicações relacionadas com o referido tema.

Ribeiro, Bellen e Nascimento (2007) investigaram a percepção dos coordenadores dos cursos de Ciências Contábeis quanto à inclusão e a forma de abordagem do ensino da temática ambiental no processo de formação dos graduandos dos cursos de ciências contábeis nas instituições de ensino superior públicas brasileiras. Os resultados da análise apontam para duas direções. A primeira, é que os coordenadores dos cursos das instituições federais estão mais conscientizados da importância do meio ambiente do que os coordenadores das instituições municipais. A segunda, é que, em regiões onde a relação com a natureza é mais presente, como no Norte, a opinião dos coordenadores entrevistados é unânime sobre a importância da temática ambiental na formação dos graduandos prática.

Diante deste cenário, é indispensável que os profissionais de contabilidade tenham o domínio sobre os conceitos que envolvem temas relevantes como Contabilidade Ambiental, estimulando discussões acadêmicas e profissionais cada vez mais intensas que corroborem para a percepção atualizada acerca dos conceitos básicos da contabilidade. O desconhecimento de tema tão atual pode indicar limitações na formação do profissional de Contabilidade.

\section{PROPOSTA DE ENSINO DA CONTROLADORIA AMBIENTAL}

O panorama atual dos cursos de graduação em Ciências Contábeis no Brasil com relação ao ensino da contabilidade ambiental revela uma visão disciplinar e fragmentada. A educação contábil

Revista de Gestão Social e Ambiental - RGSA, São Paulo, v. 6, n. 1, p. 177-189, jan./abril 2012. 
possui uma característica que privilegia a formação de um profissional técnico, que reproduz atividades pré-estabelecidas pelas organizações ou fisco, sem o desenvolvimento de uma reflexão acerca das implicações das informações na tomada de decisão e criação de valor organizacional. Ademais, o ensino sobre as questões, aqui no Brasil, privilegia os aspectos da contabilidade financeira ambiental. A maioria dos livros publicados sobre esse assunto não traz o framework da contabilidade gerencial ambiental, assim também as ementas de disciplinas fazem poucas referências aos problemas relacionados à da contabilidade ambiental gerencial.

Com relação aos conteúdos das disciplinas relacionadas à contabilidade ambiental, percebese que são ministrados de forma descontextualizada, com pouca ligação com as práticas sociais dos alunos. A Tabela 1 apresenta a ementa do componente curricular que cuida de questões socioambientais de seis IESs brasileiras. Analisando as ementas propostas por cada disciplina, percebe-se que os conteúdos mais enfatizados são sobre os aspectos da contabilidade financeira.

Desta forma, nota-se que o principal foco na formação dos estudantes de Ciências Contábeis refere-se à evidenciação de informação para os usuários externos. Isso decorre, possivelmente, da preocupação que as organizações possuem em divulgar informações de natureza ambiental que reduzam as pressões sociais, uma vez que existe um contrato implícito entre empresa e sociedade, uma vez que organizações retiram recursos naturais do ambiente para suportar suas atividades e cumprir seus objetivos, e a sociedade espera ações ambientalmente responsáveis. Neste contexto, ganha relevância o Balanço Social como instrumento de divulgação de tais informações, todavia essas informações são fornecidas com parcialidade, em razão dos interesses das organizações e dos seus gestores.

Assim, aspectos relacionados com a produção de informações estratégicas para a gestão dessas empresas ficam prejudicados, pois aspectos relacionados com os custos ambientais para o exercício de atividades específicas, gestão de resíduos, custo de oportunidade para exploração de recursos alternativos ficam excluídos da discussão desses componentes curriculares, comprometendo a formação dos futuros gestores. Acrescente-se que os alunos somente discutem questões relacionadas ao meio ambiente no momento da oferta deste componente curricular e que, na maioria, são matérias optativas. Curiosamente, são usados os mais variados nomes para este componente curricular, ainda não há padronização.

Tabela 1: Conteúdos das disciplinas relacionadas a educação ambiental contábil.

\begin{tabular}{|c|c|c|c|c|}
\hline $\begin{array}{c}\text { Instituições } \\
\text { educacionais }\end{array}$ & Disciplina & Ementa & Estado & Região \\
\hline $\begin{array}{l}\text { Universidade } \\
\text { Estadual do } \\
\text { Sudoeste da Bahia } \\
\text { - UESB }\end{array}$ & Contabilidade Ambiental & $\begin{array}{l}\text { Contabilidade Ambiental - } \\
\text { Fundamentos da Contabilidade } \\
\text { Ambiental. Aspectos financeiros, } \\
\text { patrimoniais e econômicos da } \\
\text { Contabilidade Ambiental. } \\
\text { Considerações gerais sobre a } \\
\text { Contabilidade Ambiental. } \\
\text { Contabilização. }\end{array}$ & Bahia & Nordeste \\
\hline $\begin{array}{l}\text { Faculdade José } \\
\text { Lacerda Filhos de } \\
\text { Ciências Sociais } \\
\text { Aplicadas - } \\
\text { FAJOLCA }\end{array}$ & $\begin{array}{l}\text { Contabilidade Social e } \\
\text { Ambiental }\end{array}$ & $\begin{array}{l}\text { Responsabilidade Social; } \\
\text { Responsabilidade Ambiental; } \\
\text { Balanço Social; Modelos de } \\
\text { Balanço Social; Contabilidade } \\
\text { Ambiental; Balanço Ambiental; } \\
\text { Demonstração do valor adicionado, } \\
\text { legislação aplicável. }\end{array}$ & Pernambuco & Nordeste \\
\hline $\begin{array}{l}\text { Universidade do } \\
\text { Estado do Rio } \\
\text { Grande do Norte }\end{array}$ & $\begin{array}{l}\text { Contabilidade } \\
\text { socioambiental }\end{array}$ & $\begin{array}{l}\text { Desenvolvimento econômico e } \\
\text { sustentável. Balanço social. } \\
\text { Demonstração do valor adicionado. }\end{array}$ & $\begin{array}{l}\text { Rio Grande do } \\
\text { Norte }\end{array}$ & Nordeste \\
\hline
\end{tabular}

Revista de Gestão Social e Ambiental - RGSA, São Paulo, v. 6, n. 1, p. 177-189, jan./abril 2012. 


\begin{tabular}{|c|c|c|c|c|}
\hline & & $\begin{array}{l}\text { Ativo, passivo, receitas, despesas e } \\
\text { custos ambientais. Gestão de } \\
\text { recursos naturais. }\end{array}$ & & \\
\hline $\begin{array}{l}\text { Universidade do } \\
\text { Vale do Itajaí }\end{array}$ & $\begin{array}{l}\text { Responsabilidade } \\
\text { ambiental }\end{array}$ & $\begin{array}{l}\text { Aspectos conceituais e evolução } \\
\text { histórica. Responsabilidade } \\
\text { ambiental. Empreendedorismo } \\
\text { social. Marketing social. Projetos } \\
\text { sociais. Responsabilidade social do } \\
\text { contador e das organizações. } \\
\text { Balanço social como instrumento } \\
\text { da gestão social: conceitos, } \\
\text { modelos e prática. Legislação e } \\
\text { Auditoria em balanço social. }\end{array}$ & Santa Catarina & Sul \\
\hline $\begin{array}{l}\text { Centro } \\
\text { Universitário de } \\
\text { Belo Horizonte }\end{array}$ & $\begin{array}{l}\text { Contabilidade social e } \\
\text { ambiental }\end{array}$ & $\begin{array}{l}\text { Os agregados macroeconômicos, } \\
\text { Balanço de Pagamentos, Evolução } \\
\text { Histórica da Contabilidade Social e } \\
\text { Ambiental, Principais conceitos, } \\
\text { usuários e indicadores de } \\
\text { desempenho. Demonstração do } \\
\text { valor adicionado, responsabilidade } \\
\text { social das organizações, modelos, } \\
\text { elaboração e divulgação do } \\
\text { Balanço Social e Ambiental; }\end{array}$ & Minas Gerais & Sudeste \\
\hline $\begin{array}{l}\text { Universidade } \\
\text { Federal do Rio } \\
\text { Grande do Sul }\end{array}$ & $\begin{array}{l}\text { Contabilidade Ambiental } \\
\text { e Social }\end{array}$ & $\begin{array}{l}\text { Balanço Social; Demonstração do } \\
\text { valor adicionado. Ativo, passivo e } \\
\text { resultado ambiental. Mercado de } \\
\text { carbono. Gestão de ativos e } \\
\text { passivos ambientais. Relatórios } \\
\text { ambientais. }\end{array}$ & $\begin{array}{l}\text { Rio Grande do } \\
\text { Sul }\end{array}$ & Sul \\
\hline
\end{tabular}

Fonte: dados da pesquisa.

Em busca de contribuir para que os profissionais de contabilidade tenham uma forma mais adequada com o contexto socioeconômico brasileiro e, assim, atendam a demanda do mercado por profissionais conscientes de suas responsabilidades ambientais que este artigo apresenta um framework para o ensino das questões socioambientais de forma interdisciplinar, onde o produto da relação didático-pedagógica seja de autonomia cognitiva, liberdade de pensamento, criatividade e postura crítica-reflexiva. O espaço para sustentação dessa discussão deve ser de forma contextualizada com as práticas e experiências vivenciadas pelos alunos.

Dessa forma, sugere-se a inserção do componente curricular Controladoria Ambiental, de forma obrigatória, nos cursos de Ciências Contábeis. A Controladoria Ambiental, conforme demonstra a Figura 1, identifica, mensura, acumula, analisa e interpreta as informações que ajudam os gestores na consecução das metas ambientais organizacionais e fornece informações econômicas, financeiras, físicas de produtividade que estejam relacionados com a proteção, preservação e recuperação ambiental, a fim de evidenciar a situação patrimonial de uma entidade aos diversos stakeholders. Ressalte-se que o termo Controladoria foi sugerido justamente pelo caráter interdisciplinar deste componente. 


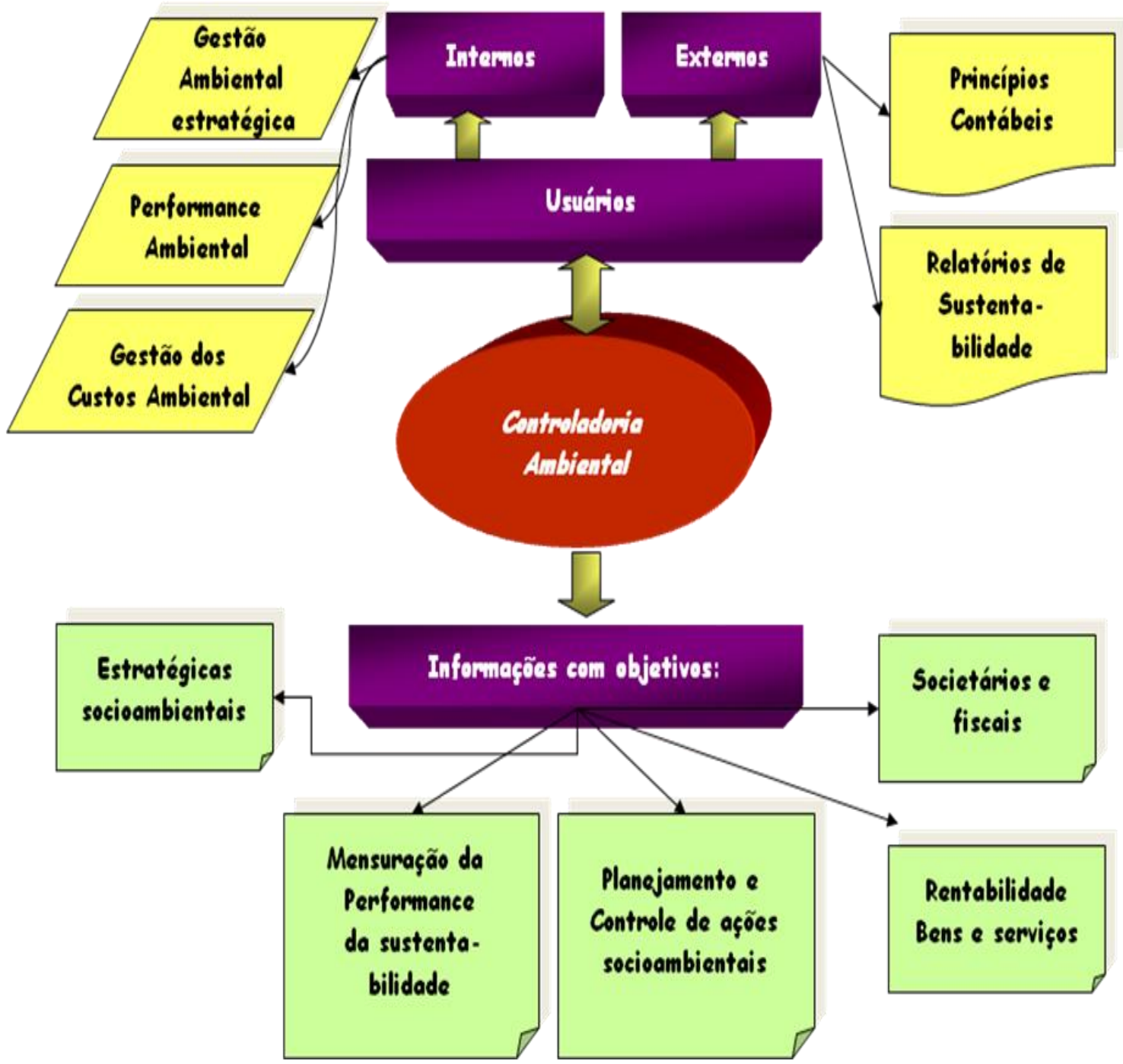

Figura 1: Controladoria ambiental.

A controladoria ambiental (conforme Figura 1) deve fornecer informações para cumprir cinco objetivos gerais: (a) permitir a formulação de estratégias e dos planos de ações de longo prazo sobre as questões socioambientais; (b) possibilitar as decisões sobre a utilização dos recursos pelas atividades, com ênfase tanto no cliente quanto no preço; (c) o planejamento e controle de custo das ações socioambientais que compõem o Sistema de Gestão Ambiental da Empresa; (d) mensuração da performance e avaliação dos impactos socioambientais; e por fim (e) elaborar e divulgar as informações socioambientais em conformidade com os princípios contábeis e das legislações societárias e fiscais.

Já as informações geradas pela Controladoria Ambiental para os usuários internos devem ser modeladas para atender as demandas da gestão estratégica, dos processos e da performance, permitindo-lhes tomar decisões sobre os impactos socioambientais que consomem os recursos e contribuem para o desempenho empresarial. Isso porque a agregação de valor ao negócio e, em última análise, ao proprietário ocorre pelo resultado operacional positivo, ou seja, o valor da venda do produto supera os recursos sacrificados para sua produção. Na perspectiva da empresa, o valor agregado é gerado para os seus proprietários quando há lucro líquido decorrente das relações de compra e venda Por conseguinte, é o valor percebido e pago pelo cliente, em contrapartida à aquisição do produto, e que supera seus custos de produção. Outrossim, esse valor agregado 
constitui a base do processo de remuneração e acumulação de capitais. Desse modo, o valor agregado vem de fora da empresa, pela atividade comercial e não pela atividade de produção ou pelas operações de serviço.

As informações fornecidas pela Controladoria Ambiental para a tomada de decisão da Gestão Ambiental Estratégica devem possibilitar a organização definir suas metas estratégicas para redução dos custos ambientais, buscando fortalecer seus pontos fracos em relação aos concorrentes: definir missão, visão, valores e princípios de sustentabilidade; o escopo da Responsabilidade Social Corporativa (RSC); os instrumentos para integrar os impactos ambientais nas decisões gerenciais. Para tanto, utilizará como ferramentas: a análise de custos e de investimento e a avaliação de desempenho.

Para os gestores tomarem decisão sobre a Gestão dos Custos Socioambientais a Controladoria Ambiental deve fornecer informações que auxiliam na definição das atividades, processos e produtos que causam custo ambiental, são os seguintes: a) classificação dos custos ambientais; b) avaliação de ciclo de vida do produto; c) departamentalização dos custos ambientais; d) custeio baseado em atividades; e) quantificação e monetarização das externalidades e custos ambientais das atividades da cadeia de valor. Os custos ambientais, por sua vez, podem ser classificados em: custos de preservação ambiental, custos de detecção ambiental, custos de falhas ambientais internas e externas. A Controladoria Ambiental, ao fazer análise de investimento socioambiental, pode utilizar como instrumentos de gestão: avaliação do custo total e de multicritério e análise de incerteza e riscos.

As informações fornecidas pela Controladoria Ambiental para a tomada de decisão da Gestão da Performance Ambiental devem possibilitar que a organização tome decisões sobre avaliação de desempenho, para tanto deve utilizar os seguintes instrumentos: avaliações com base nas estratégias ambientais das unidades de negócios; incentivos individuais; multiplicadores ambientais; taxas ambientais e redução de resíduos; Balanced Scorecard.

Em relação às informações para os usuários externos, a Controladoria Ambiental deve demonstrar para os stakeholders as transações ambientais que afetam a posição econômica e financeira da empresa, devendo assegurar que os elementos do patrimônio estejam reconhecidos e mensurados de acordo com as práticas de contabilidade e legislações pertinentes. Para isso, conta com os seguintes instrumentos: o Balanço Ambiental e Social e ou o Relatório de Sustentabilidade.

Com o propósito de alcançar os objetivos descritos para Controladoria Ambiental, esse componente curricular deveria ter como ementa: Sustentabilidade; Sistema de gestão Ambiental; Instrumentos de mensuração de custos ambientais (avaliação de ciclo de vida do produto; análise de custo-benefício; custeio baseado em atividade; custos das externalidades); Logística Reversa; Medição e avaliação do desempenho ambiental; Reconhecimento, mensuração e divulgação das atividades socioambientais e Relatórios de Sustentabilidade. É importante que os estudantes sejam preparados com conteúdos: Teorias Econômicas, Teoria da Contabilidade, Sistemas Organizacionais, Matemática, Métodos Quantitativos, Contabilidade e Análise de Custos.

Caso o projeto político pedagógico do curso (PPP) defina que as questões socioambientais serão discutidas em um componente curricular optativo, sugere-se, então, o desenvolvimento de um Projeto Temático Interdisciplinar, em que os componentes do curso trabalhem essa temática de maneira transversal. Por exemplo, o tema a ser discutido pelos professores seria: Degradação do meio ambiente gerada pela indústria $\mathrm{Y}$ de cosméticos na Região $\mathrm{Z}$. O detalhamento de como os outros componentes poderiam participar está descrito na Figura 2. O professor definiria a maneira de envolver os estudantes no desenvolvimento do Projeto Temático, se por meio de seminário, visita técnica, elaboração de artigos científicos, entre outros.

\begin{tabular}{|l|l|l|}
\hline Tema do projeto & \multicolumn{1}{|c|}{ Disciplinas relacionadas } & \multicolumn{1}{c|}{ Conteúdos sugeridos para discussão } \\
\hline & Controladoria Ambiental & $\begin{array}{l}\text { Externalidades negativas, avaliação dos impactos ambientais } \\
\text { e relatórios gerenciais e de sustentabilidade. }\end{array}$ \\
\hline
\end{tabular}

Revista de Gestão Social e Ambiental - RGSA, São Paulo, v. 6, n. 1, p. 177-189, jan./abril 2012. 


\begin{tabular}{|c|c|c|}
\hline \multirow{6}{*}{$\begin{array}{l}\text { Degradação do } \\
\text { meio ambiente } \\
\text { gerada pela } \\
\text { indústria Y de } \\
\text { cosméticos na } \\
\text { cidade X. }\end{array}$} & Teoria da contabilidade & $\begin{array}{l}\text { Normas e práticas contábeis relacionadas ao meio ambiente; } \\
\text { mensuração dos elementos do patrimônio e teoria de } \\
\text { evidenciação dos impactos ambientais. }\end{array}$ \\
\hline & Contabilidade de custos & $\begin{array}{l}\text { Identificação do método de custeio para tratamento do } \\
\text { resíduo industrial. }\end{array}$ \\
\hline & Contabilidade governamental & $\begin{array}{l}\text { Identificação das despesas de custeio para recuperar a } \\
\text { qualidade dos ribeirinhos e ou dos que são afetados pelos } \\
\text { resíduos industriais. }\end{array}$ \\
\hline & Ética geral e profissional & $\begin{array}{l}\text { Responsabilidade social do profissional de contabilidade; } \\
\text { missão, valores e princípios socioambientais da empresa. }\end{array}$ \\
\hline & Contabilidade tributária & $\begin{array}{l}\text { Legislações ambientais e contabilização de impostos e } \\
\text { multas. }\end{array}$ \\
\hline & Auditoria & $\begin{array}{l}\text { Parecer sobre as demonstrações contábeis quanto à } \\
\text { degradação do meio ambiente gerado pelo não tratamento dos } \\
\text { resíduos industriais. }\end{array}$ \\
\hline
\end{tabular}

Figura 2: Proposta de projeto interdisciplinar em controladoria ambiental.

Fonte: Elaborado pelos autores.

Nessa perspectiva, este componente curricular deverá estar alicerçado no paradigma da sustentabilidade. Ademais, todos os componentes curriculares do curso devem forçar temas transversais, que proporcionem a discussão acerca do desenvolvimento sustentável, responsabilidade social corporativa, geração de informações ambientais estratégicas, contabilização das ações de prevenção e recuperação do meio ambiente, além dos conteúdos já discutidos pela tradicional contabilidade ambiental.

\section{CONSIDERAÇÕES FINAIS}

O objetivo deste trabalho foi apresentar uma proposta de ensino da Controladoria Ambiental nos Cursos de Ciências Contábeis das Instituições de Ensino Superior (IES) brasileiras. As pesquisas empíricas confirmam que há necessidade de inserção das questões ambientais na formação do profissional de Contabilidade e uma demanda crescente de profissionais que dominem os instrumentos de gestão dos impactos socioambientais.

Pelo fato de os estudantes serem os futuros tomadores de decisões corporativas, a inserção da variável ambiental na educação é um tema importante e as instituições de negócios deveriam encorajar esta prática. Todavia, existem diversas dificuldades para inserção das questões ambientais na formação dos profissionais de contabilidade, tendo em vista que este assunto, na opinião da maioria dos coordenadores de cursos, não é emergente, tanto que faltam referências adequadas para alunos de graduação e docentes qualificados. Outra questão apontada refere-se às dificuldades da introdução da questão ambiental no currículo, com a prática de gestão ambiental com enfoque multidisciplinar.

Além do mais, o modelo de ensino atual sobre as questões socioambientais é fragmentado e disciplinar (contabilidade financeira ambiental e contabilidade gerencial ambiental). Ainda são poucas as IESs que já inseriram as questões ambientais na matriz curricular. Os assuntos tratados são bem diversificados

Assim, como contribuição para que as questões ambientais façam parte da formação dos profissionais de contabilidade, propõe-se um modelo de ensino interdisciplinar, alicerçado na abordagem de sustentabilidade da matéria controladoria ambiental como obrigatória. A Controladoria Ambiental deve fornecer informações para cumprir cinco objetivos gerais: (a) permitir a formulação de estratégias e dos planos de ações de longo prazo sobre as questões a socioambientais; (b) possibilitar as decisões sobre a utilização dos recursos pelas atividades, com ênfase tanto no cliente, quanto no preço; (c) o planejamento e controle de custo das ações socioambientais que compõem o Sistema de Gestão Ambiental da Empresa; (d) mensuração da 
performance e avaliação dos impactos socioambientais; e por fim (e) elaborar e divulgar as informações socioambientais em conformidade com os Princípios Contábeis e das legislações societárias e fiscais.

\section{REFERÊNCIAS}

Bae, B., Sami, H. (Wint, 2005) The effect of potential environmental liabilities on earnings response coefficients. Journal of Accounting, Auditing \& Finance, 20(1), 43-70.

Borba, J.A., Rover, S. (2006) A evidenciação das informações ambientais nas demonstrações contábeis das empresas que atuam no Brasil e que negociam na bolsa de valores dos Estados Unidos: Uma análise das DFPs (CVM) e do relatório 20-F (SEC). Trabalho apresentado no Congresso de Contabilidade da USP. São Paulo

Canning, J.B.(1929) Economics of accountancy: a critical analisis of accounting theory. New York: Ronald.

Castro, M.A.R.(2008) Análise do alisamento de resultados contábeis nas empresas abertas brasileira. Dissertação (Mestrado) Universidade Federal da Bahia - UFBA.

CFC - Conselho Federal de Contabilidade. Resolução CFC 1.003 de 19.08.2004. NBC T 15. Informações de natureza social e ambiental. Recuperado em 2 julho de 2010, de: < http://www.cfc.org.br/sisweb/sre/Default.aspx>.

Farias, M.R.S.(2006) Bases conceituais e normativas para reconhecimento e divulgação do passivo contingente: um estudo empírico no setor químico e petroquímico brasileiro. de São Paulo. Anais Congresso USP de Controladoria e Contabilidade, 6. Recuperado em 12 de abril 2009, de: <www.congressousp.fipecafi.org/artigos62006/477.pdf>.

FASB - Financial Accounting Standards Board. (edition 2002/2003) Accounting Standards: Current Text, v. 1 General Standards Topical Index, John Wiley: New York.

FASB - Financial Accounting Standards Board.( edition 2002/2003). Accounting Standards. SFAS 5 Statement of Financial Accounting Standards n5. Accounting for Contingencies. Issued: March 1975, IN: Financial Accounting Standards Board - Original Pronouncements. John Wiley: New York,

GRI - Global Reporting Iniciative. (2010) Diretrizes para Relatórios de Sustentabilidade. Recuperado em 2 julho de 2010, de://www.globalreporting.org>.

Hendriksen, E.S., Breda, M.F.V (2007) Teoria da contabilidade. Tradução de Antônio Zoratto Sanvicente.- 5. ed. São Paulo: Atlas.

INEP - Instituto Nacional de Estudos e Pesquisas Educacionais. Recuperado em 4 de maio de 2009, de: 〈http://www.educacaosuperior.inep.gov.br/funcional/lista_cursos.asp>.

Nascimento, A.R. do et al.(2009) Disclosure social e ambiental: análises das pesquisas científicas veiculadas em periódicos de língua inglesa. Revista Contabilidade Vista \& Revista. Universidade Federal de Minas Gerais. 20(1), 15-40.

Nossa, V. (2002) Disclosure ambiental: uma análise do conteúdo dos relatórios ambientais de empresas do setor de celulose em nível internacional? 2002. 249 f. Tese (Doutorado) Universidade de São Paulo - USP.

Niyama, J. K., Silva, C. A. T. (2008) Teoria da contabilidade. São Paulo: Atlas

Revista de Gestão Social e Ambiental - RGSA, São Paulo, v. 6, n. 1, p. 177-189, jan./abril 2012. 
Paiva, P.R. de. (2003) Contabilidade ambiental: evidenciação dos gastos ambientais com transparência e focada na prevenção. São Paulo: Atlas.

Ribeiro, M. de S.(2005) O tratamento contábil dos créditos de carbono. Tese (Livre Docência) Universidade de São Paulo - USP.

Souza, V. R., Ribeiro, M. de S. (2004) Aplicação da contabilidade ambiental na indústria madeireira. Revista de Contabilidade \& Finanças - USP. São Paulo, (35), 54-67.

Patten, D. M. (1992) Intra-industry environmental disclosures in response to the alaskan oil spill: a note on legitimacy theory. Accounting, Organizations and Society. 15(5), 471-475.

Data do recebimento do artigo: 06/05/2011

Data do aceite de publicação: 05/03/2012 